\title{
Late malignant transformation of vestibular schwannoma in the absence of irradiation: case report
}

\author{
Asma Bashir, MD, ${ }^{1}$ Lars Poulsgaard, MD, ${ }^{1}$ Helle Broholm, MD, ${ }^{2}$ and \\ Kåre Fugleholm, MD, PhD, FRCS ${ }^{1}$ \\ Departments of ${ }^{1}$ Neurosurgery and ${ }^{2}$ Pathology, Rigshospitalet, Faculty of Health and Medical Sciences, University of
Copenhagen, Denmark
}

Late malignant transformation of vestibular schwannoma (VS) following irradiation has previously been reported 29 times in the literature. Here, the authors report the first late malignant transformation of VS unrelated to neurofibromatosis or radiation exposure. After undergoing a near-total excision of a histologically benign VS, the patient developed malignant regrowth of the tumor remnant 42 months after the primary excision. This case challenges the dogmatic belief of absolute causality between radiation exposure and late malignant transformation of VS, and has important implications regarding future counseling and consent for the treatment of patients with VS.

http://thejns.org/doi/abs/10.3171/2015.6.JNS1544

KEY WORDS vestibular schwannoma; tumor recurrence; MIB-1 index; malignant transformation; malignant peripheral nerve sheath tumor; oncology

$\mathrm{M}$ ALIGNANT transformation of vestibular schwannoma (VS) following irradiation has previously been reported 29 times in the literature with a mean delay of 85 months after the treatment. ${ }^{28}$ Here, we present the first case of late malignant transformation of benign VS in a patient with no history of neurofibromatosis Type 2 (NF2) or previous radiation exposure, and in a window of time comparable with that observed for malignant transformation after irradiation.

\section{Case Report}

History and Examination

In August 2010, a 47-year-old female patient presented with a 6-month history of right-sided gradual hearing loss, tinnitus, and balance disturbance, and a 10-month history of right facial numbness. The patient had neither a family history nor features of NF2, or any history of radiation exposure. Neurological examination revealed decreased sensation on the right side of her face involving the first and second branches of the trigeminal nerve, sensorineural hearing loss, and a positive Romberg's test. Caloric testing showed abolished vestibular function on the right side. MRI of the brain demonstrated a contrast-enhancing mass, with a size of $31 \mathrm{~mm}$ in the largest extrameatal diameter, in the right cerebellopontine angle, and a slightly enlarged meatus (Fig. 1A).

\section{Operation and Histological Examination}

The patient underwent a near-total tumor excision via a translabyrinthine approach. The tumor tissue was adherent

ABBREVIATIONS MPNST = malignant peripheral nerve sheath tumor; NF2 = neurofibromatosis Type 2; SRS = stereotactic radiosurgery; SRT = stereotactic radiotherapy; VS = vestibular schwannoma. 

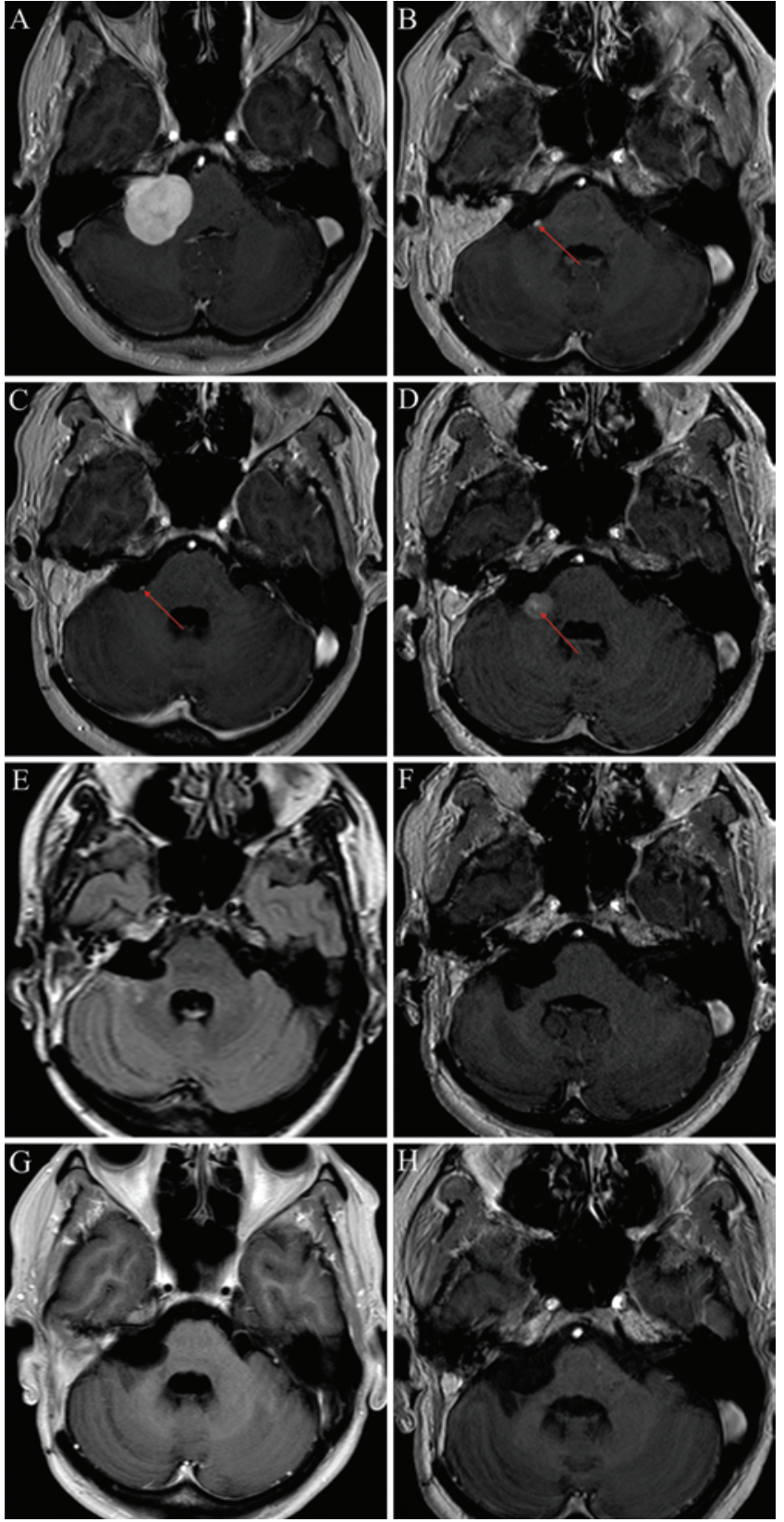

FIG. 1. Axial T1-weighted MR images showing a contrast-enhancing VS in the right cerebellopontine angle at the time of diagnosis (A), the residual tumor 6 months after the first operation (arrow, B), the residual tumor 24 months later (arrow, C), and tumor enlargement 42 months later (arrow, D); and absence of tumor after the second operation (E), 3 months after irradiation (F), 6 months after irradiation (G), and 9 months after irradiation $(\mathbf{H})$.

to the facial nerve, and a small remnant of the tumor was left behind on the nerve. After surgery, the patient exhibited a right-sided facial nerve palsy (House-Brackmann Grade IV) and was discharged home 5 days later. Histologically, the tumor tissue was typically biphasic and was composed of glial fibrillary cells. These were arranged in interlacing fascicles, sometimes with nuclei aligned in a palisading pattern (but with no characteristic Verocay bodies), and intermingled with a more cystic glial tissue. Positive immunoreactivity for S100 protein was present universally, and MIB-1 labeling index was less than $2 \%$ (Fig. 2A-E). The histological diagnosis was a typical benign VS, WHO Grade I.

\section{Postoperative Radiological Surveillance}

Six months later, MRI showed a small residual tumor on the brainstem near the cerebellar peduncle (Fig. 1B). At this stage, the patient had regained facial nerve function (House-Brackmann Grade II). We decided to monitor the patient with serial MR images, which showed no change in the residual tumor size the following 24 months (Fig. $1 \mathrm{C})$. The patient did not receive radiation treatment.

\section{Tumor Recurrence and Second Operation}

In February 2014, 42 months after the primary excision, the patient developed a right-sided facial paralysis (House-Brackmann Grade VI) over a period of 2 months. Now, MRI revealed progression in size of the residual tumor, measuring $10 \times 10 \mathrm{~mm}$ and deeply embedded in the cerebellar peduncle (Fig. 1D). A second translabyrinthine tumor excision was performed. As the facial nerve was infiltrated by tumor tissue and the frozen section analysis suggested malignancy, the tumor was completely excised including a section of the facial nerve. Postoperatively, the patient recovered quickly and was discharged from the hospital 3 days later with facial nerve paralysis. Histological examination now demonstrated a tumor tissue of an infiltrative nature with hypercellularity and focally pleomorphic cells in a fascicular arrangement. There were 15-20 mitoses per $10 \mathrm{hpf}$, with the MIB-1 labeling index of up to $50 \%$ in some areas. The immunoreactivity for $\mathrm{S} 100$ protein was only positive focally (Fig. 3A-F). Furthermore, immunohistochemistry for $\mathrm{p} 53$ showed strong diffuse staining in the tumor tissue, indicating enhanced expression of mutant p53 protein (Fig. 3G and $\mathrm{H}$ ), but not in the tumor obtained at first resection (Fig. 2F). The features resembled a sarcomatous change, and the final histological diagnosis was a malignant peripheral nerve sheath tumor (MPNST).

\section{Stereotactic Radiotherapy and Outcome}

A month after the second excision, the patient underwent a hypoglossal-facial nerve anastomosis to reanimate her face. The patient was then referred to another center for adjuvant stereotactic radiotherapy (SRT) to the tumor bed (1.8 Gy per fraction, 30 fractions total). At the time of irradiation, no visible tumor mass was seen on MRI (Fig. 1E). The patient tolerated the treatment well and completed it by the end of June 2014. Since then, the patient has been followed in the outpatient clinic with clinical evaluations and MRI scans every 3 months. The patient has been clinically stable as of this writing, apart from complaints of occasional dizziness, and without any signs of tumor recurrence 9 months after irradiation as assessed by serial MRI (Fig. 1F-H).

\section{Discussion}

Malignant transformation of a histologically benign VS is extremely rare. To our knowledge, the present case is 

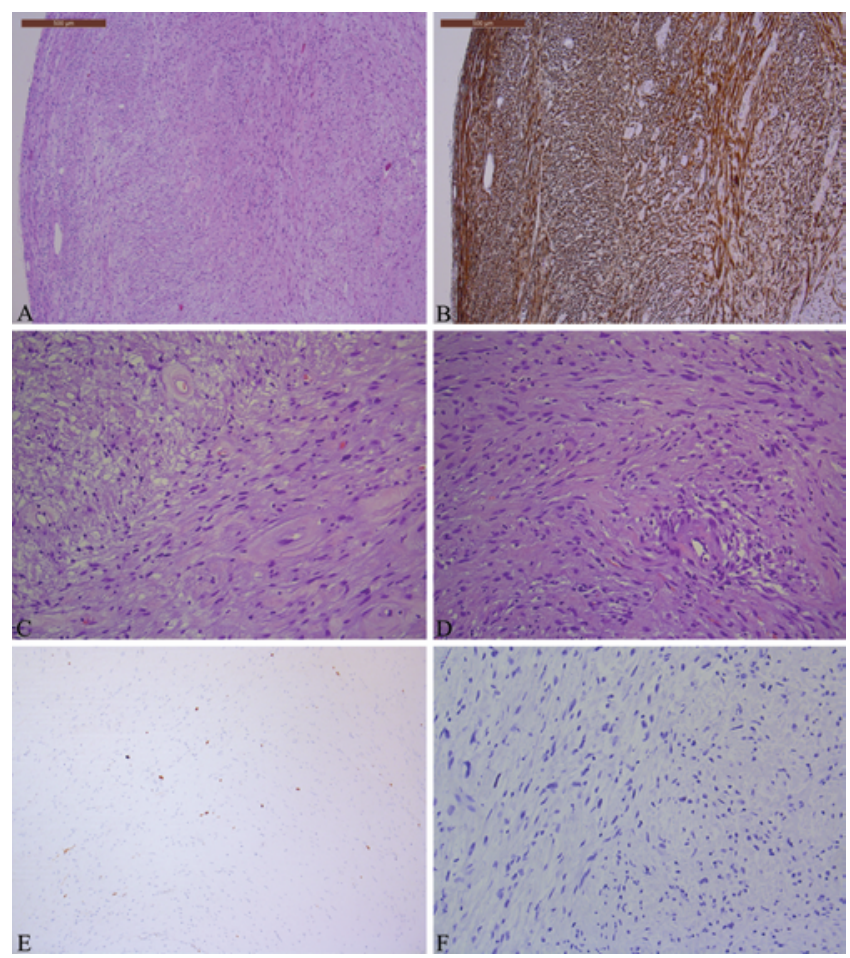

FIG. 2. Histological examination of primary tumor resection showing an ordinary VS with long glial cells, fascicular orientated with numerous intermingled macrophages (A, H \& E), universal positivity for S100 protein (B) with both Antoni $A$ and Antoni $B$ areas and characteristic hyalinized vessels (C, $\mathrm{H} \& \mathrm{E})$; a higher magnification of the tumor from a more compact area (Antoni A pattern), with characteristic long Schwann cells with normochromatic nuclei, and an eosinophilic cytoplasm with indistinct borders (D, H \& E); an MIB-1 labeling index less than 2\% (E, Ki 67); and negative immunostaining for p53 (F). Original magnification $\times 50(A$, $B$, and $E) ; \times 200(C, D$, and F). Figure is available in color online only.

the first histologically confirmed report of late malignant transformation of a previously benign VS with no predisposing factors such as NF2 or previous irradiation. In the published literature, a total of 20 cases of malignant VS in the absence of aforementioned risk factors have been reported (Table 1). ${ }^{3,5,8,10-12,14,16,17,19,21,23-25,27,29,31,33}$ Of these, only 4 cases have been reported with a benign histology of VS before undergoing malignant transformation. ${ }^{24,29,31}$ Two of these cases deserve special attention. ${ }^{24,31}$ Son et al. ${ }^{31}$ described histological features consistent with early malignant progression from a benign VS. They confirmed the benign nature of VS histologically before it transformed into a malignant schwannoma after only 2 months in contrast to the latency of 42 months in our case. One might suggest that the primary tumor in the case of Son et al. ${ }^{31}$ had both malignant and benign components. However, due to a possible sampling error of the first tumor specimen, the malignant component was not discovered histologically, and therefore, a rapid recurrence was observed 2 months later. Postoperative scanning consisted of CT scanning only, and not MRI. This might explain the recurrence, and thus enlargement of a possible residual tumor, as CT scanning is insufficient to verify gross tumor excision. McLean et al. ${ }^{24}$ were the first to report malignant
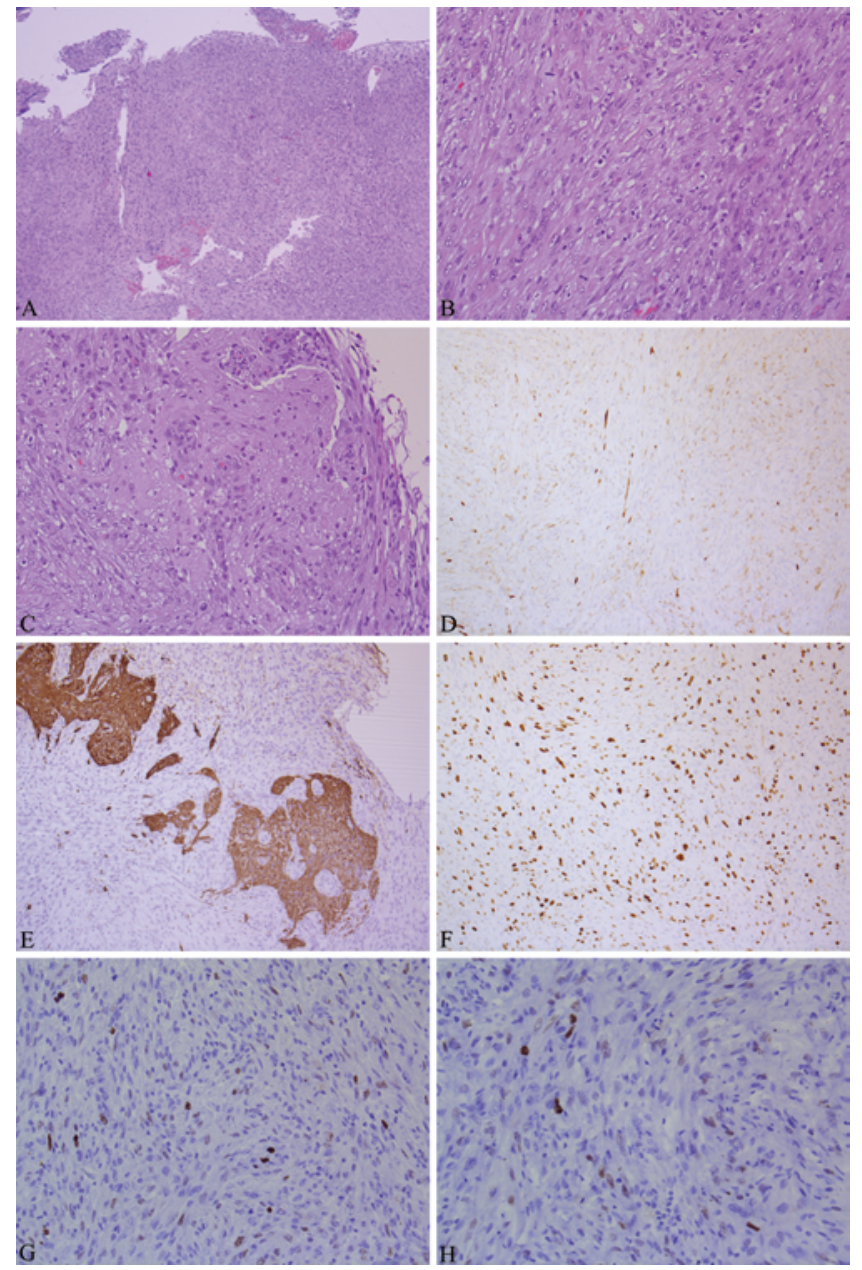

FIG. 3. Histological examination of recurrent tumor, a highly cellular pleomorphic tumor $(\mathbf{A}, \mathrm{H} \& \mathrm{E})$ with many mitoses $(\mathbf{B}, \mathrm{H} \& \mathrm{E})$ and clear invasion in the surrounding parenchyma $(C, H \& E)$ and only sparse positivity for S100 protein in the tumor tissue (D, S100). The same area showing the brain parenchyma like islands surrounded by tumor tissue (E, GFAP); MIB-1 index constituting up to $50 \%$ (F, Ki 67); and diffuse positive immunostaining for $p 53$, suggesting expression of mutant $p 53$ ( $G$ and $H)$. Original magnification $\times 50(A) ; \times 200(B, C$, and $G) ; \times 100$ $(\mathrm{D}-\mathrm{F}) ; \times 400(\mathrm{H})$. Figure is available in color online only.

transformation of VS after initial surgery. However, small areas of malignant characteristics including increased cellularity and mitotic figures were already present in the histological examination of the primary VS. Hence, this schwannoma might have been malignant from the outset.

It has previously been suggested that an elevated MIB1 labeling index (normal range $<2 \%$ ) might reflect a predisposition for malignant transformation and might correlate with a high risk of regrowth of tumor after partial or near-total resection. ${ }^{9,34}$ Neither of the above-reported studies $^{24,31}$ and cases reported by Scheithauer et al. ${ }^{29}$ mentioned the MIB-1 index of the primary tumor. Son et al. ${ }^{31}$ reported scattered MIB-1-positive cells with an index of the first and second recurrent tumor constituting 3\% and $2 \%$, respectively. This is remarkable because of the rapid tumor growth within a very short time frame, similar to the behavior of a "biologically aggressive" schwannoma. ${ }^{18}$ 
TABLE 1. Published papers on malignant VS in the absence of NF2 and radiation exposure

\begin{tabular}{|c|c|c|c|c|c|c|c|}
\hline Authors \& Year & $\begin{array}{l}\text { Age (yrs), } \\
\text { Sex }\end{array}$ & Location & Primary Pathology & $\begin{array}{l}\text { Secondary } \\
\text { Pathology }\end{array}$ & Latency & Management & $\begin{array}{l}\text { Outcome } \\
\text { (survival) }\end{array}$ \\
\hline Kudo et al., 1983 & $54, \mathrm{M}$ & Rt CN VIII & MPNST & & & Surgery & $1 \mathrm{mo}$ \\
\hline $\begin{array}{l}\text { Hernanz-Schulman et } \\
\text { al., } 1986\end{array}$ & $2, F$ & NA CN VIII & MPNST & & & Surgery & NA \\
\hline Best, 1987 & $24, F$ & Rt CN VIII & Triton & & & Surgery & 4 mos \\
\hline McLean et al., 1990 & $75, M$ & Rt CN VIII & $\begin{array}{l}\text { Acoustic neurilemoma w/ malig- } \\
\text { nant features, MIB-1 NA }\end{array}$ & MPNST & $11 \mathrm{mos}$ & Surgery & $2 \mathrm{mos}$ \\
\hline Matsumoto et al., 1990 & $59, \mathrm{M}$ & Rt CN VIII & MPNST & & & Surgery & $5 \mathrm{mos}$ \\
\hline Han et al., 1992 & $47, \mathrm{~F}$ & Rt CN VIII & Triton & & & Surgery & $11 \mathrm{mos}$ \\
\hline Maeda et al., 1993 & $38, M$ & Rt CN VIII & Triton & & & Surgery & 3 mos \\
\hline Mrak et al., 1994 & $40, \mathrm{M}$ & Lt CN VIII & Malignant VS & & & Surgery + irradiation & $36 \mathrm{mos}$ \\
\hline Earls et al., 1994 & $77, \mathrm{M}$ & Lt CN VIII & Malignant melanotic schwannoma & & & Surgery & NA \\
\hline Gruber et al., 1994 & $61, F$ & Rt CN VIII & Malignant VS & & & Surgery & Stable \\
\hline Saito et al., 2000 & $69, \mathrm{M}$ & Lt CN VIII & MPNST & & & Surgery & NA \\
\hline Harada et al., 2000 & $7, \mathrm{M}$ & Rt CN VIII & $\begin{array}{r}\text { Acoustic schwannoma w/ few } \\
\text { mitotic figures, MIB-1 2.3\% }\end{array}$ & $N A^{*}$ & $9 \mathrm{mos}$ & Surgery + irradiation & NA \\
\hline Son et al., 2001 & $33, F$ & Lt CN VIII & VS, MIB-1 NA & $\begin{array}{l}\text { Malignant } \\
\text { schwannoma }\end{array}$ & $2 \mathrm{mos}$ & Surgery + irradiation & Stable \\
\hline Gonzalez et al., 2007 & $43, F$ & Lt CN VIII & Malignant VS & & & Surgery + irradiation & $8 \mathrm{mos}$ \\
\hline Chen et al., 2008 & $62, \mathrm{~F}$ & Lt CN VII/VIII & MPNST & & & Surgery & $4 \mathrm{mos}$ \\
\hline \multirow[t]{3}{*}{$\begin{array}{l}\text { Scheithauer et al., } \\
2009\end{array}$} & $56, \mathrm{M}$ & Rt CN VIII & $\begin{array}{l}\text { VS w/ degenerative changes, } \\
\text { MIB-1 NA }\end{array}$ & MPNST & $7 \mathrm{mos}$ & Surgery & $2 \mathrm{mos}$ \\
\hline & $67, \mathrm{M}$ & Rt CN VIII & VS, MIB-1 NA & MPNST & 9 mos & Surgery & $1 \mathrm{mo}$ \\
\hline & $5, M$ & Lt CN VIII & MPNST & & & Surgery & Stable \\
\hline Karami et al., 2011 & $23, \mathrm{~F}$ & Lt CN VIII & MPNST & & & Surgery + irradiation & $27 \mathrm{mos}$ \\
\hline Wei et al., 2012 & $41, \mathrm{~F}$ & Rt CN VIII & MPNST & & & Surgery & NA \\
\hline Present case & $47, \mathrm{~F}$ & Rt CN VIII & VS, MIB-1<2\% & MPNST & 42 mos & Surgery + irradiation & Stable \\
\hline
\end{tabular}

$\mathrm{CN}=$ cranial nerve; $\mathrm{NA}=$ not available.

* MIB-1 before and after irradiation constituting $4.6 \%$ and $14.7 \%$, respectively.

In our case study, the MIB-1 labeling index was less than $2 \%$, confirming the benign nature of the primary tumor, thus indicating a favorable prognosis.

In recent years, the use of stereotactic radiosurgery (SRS) or SRT has been shown to be an effective alternative to microsurgical removal of most small- to medium-sized VSs with tumor control rates as high as $97 \%$, with preservation of nerve function and minimum risk of damage to surrounding neuronal structures. ${ }^{6,15,20}$ However, there is a concern that irradiation itself might play a causative role in secondary malignancy, which is a rare but a serious complication after radiation treatment, as reported in several case reports. ${ }^{17,20,30,34}$ In a large study of 440 patients treated with Gamma Knife surgery for VS and with a median follow-up period of 12.5 years, the authors reported only one case of developing malignant change. The overall malignant transformation rate was calculated to $0.3 \%$, with an annual incidence of $0.02 \%$. However, there was no histological confirmation of the tumor type before irradiation. ${ }^{15}$ Patel and Chiang ${ }^{26}$ reviewed 36 cases of SRSinduced neoplasms, half of them having initial diagnosis of VS $(n=22)$. Thirteen of these VSs transformed into MPNST, 5 developed glioblastoma, and the remaining were sarcomas. The authors estimated the risk of developing a malignancy after SRS for any benign lesion to be $0.04 \%$ at 15 years postirradiation. Until recently, there has been no accurate quantification of the risk of malignant transformation of irradiated versus nonirradiated VSs. In a recent review by Seferis et al., ${ }^{28}$ the authors estimated that the overall risk of malignancy over 20 years in cases in which radiation treatment has occurred was 15.6 per $100,000(0.016 \%)$, while this risk decreased to $1.09-1.74$ per $100,000(0.001 \%-0.002 \%)$ in cases of no radiation exposure. However, the true incidence of radiation-induced neoplasms is rather difficult to estimate, given the individual case reports with different sources of radiation, total radiation dose, and number of treatments, lack of histopathology of the primary tumor, and a postradiation followup period of less than 15 years.

Traditionally, to be considered a radiation-induced malignancy, the tumor must fulfill Cahan's criteria, ${ }^{4}$ established in 1948, which included: 1) the new tumor must occur within the previously irradiated field, and should not be present at the time of irradiation; 2) a sufficient latency period is required between the time of irradiation and development of the new tumor; 3) the new tumor is 
histologically distinct from the primary tumor; and 4) the patient should not have a genetic predisposition for cancer development. Several case reports lack a histological diagnosis of the primary tumor prior to irradiation. ${ }^{15,30} \mathrm{It}$ might be due to the fact that the primary diagnosis is often presumptive, based on the imaging characteristics of the tumor only, and SRS or SRT is performed as a primary treatment without any histological investigation. This can increase the risk of an erroneous diagnosis of the irradiation-induced malignant transformation of the tumor. In 2 case reports, malignant transformation occurred only 6 months after SRS. ${ }^{13,28}$ The short latency period in these cases could indicate that a malignant component already existed prior to irradiation, and might be aggravated by it, as radiation-induced malignancy usually develops over a longer period of time. ${ }^{1,722,30}$ However, there is no consensus on the minimum latency period between radiation exposure and tumor development, and further work is necessary to establish a reference latency interval for radiation-induced tumors. Finally, in some case reports, patients with malignant VS have underlying NF2, a genetic condition known to be associated with a higher risk of malignant tumors, especially after radiation treatment, ${ }^{2,32}$ and which contests Cahan's Criterion $4 .{ }^{4}$ Baser et al. ${ }^{2}$ surveyed 1348 patients with NF2 and reported that patients with NF2 had a 14-fold increased risk of developing malignant brain tumors after irradiation compared with patients without NF2. Tanbouzi Husseini et al. ${ }^{32}$ suggested that irradiation could serve as a final genetic hit that might induce a second tumor or malignant transformation in already mutated cells.

The causal association between irradiation and secondary transformation of VS has not clearly been demonstrated. The malignant transformation in the absence of irradiation in our case raises the question of whether the rare malignant transformation seen after radiation exposure represents a natural course of the disease rather than an effect of radiation exposure.

\section{Conclusions}

The present report is the first histologically confirmed case of late malignant transformation of VS in the absence of NF2 and previous irradiation, where a benign VS spontaneously became malignant with a latency period similar to that observed for malignant transformation after irradiation. Our case challenges the dogmatic belief of absolute causality between irradiation and late malignant transformation of VS and has important implications for future counseling and consent for treatment of patients with VS. We believe that rare case reports of secondary malignancy following irradiation should not deter physicians from its use, but caution is required when counseling patients, particularly young patients, with a genetic predisposition to cancers.

\section{References}

1. Akamatsu Y, Murakami K, Watanabe M, Jokura H, Tominaga T: Malignant peripheral nerve sheath tumor arising from benign vestibular schwannoma treated by gamma knife radiosurgery after two previous surgeries: a case report with surgical and pathological observations. World Neurosurg 73:751-754, 2010

2. Baser ME, Evans DGR, Jackler RK, Sujansky E, Rubenstein A: Neurofibromatosis 2 , radiosurgery and malignant nervous system tumours. Br J Cancer 82:998, 2000

3. Best PV: Malignant triton tumour in the cerebellopontine angle. Report of a case. Acta Neuropathol 74:92-96, 1987

4. Cahan WG, Woodard HQ, Higinbotham NL, Stewart FW, Coley BL: Sarcoma arising in irradiated bone; report of 11 cases. Cancer 1:3-29, 1948

5. Chen L, Mao Y, Chen H, Zhou LF: Diagnosis and management of intracranial malignant peripheral nerve sheath tumors. Neurosurgery 62:825-832, 2008

6. Chung WY, Liu KD, Shiau CY, Wu HM, Wang LW, Guo WY, et al: Gamma knife surgery for vestibular schwannoma: 10-year experience of 195 cases. J Neurosurg 119 Suppl:87-97, 2013

7. Demetriades AK, Saunders N, Rose P, Fisher C, Rowe J, Tranter R, et al: Malignant transformation of acoustic neuroma/vestibular schwannoma 10 years after gamma knife stereotactic radiosurgery. Skull Base 20:381-387, 2010

8. Earls JP, Robles HA, McAdams HP, Rao KC: General case of the day. Malignant melanotic schwannoma of the eighth cranial nerve. Radiographics 14:1425-1427, 1994

9. Fukuda M, Oishi M, Hiraishi T, Natsumeda M, Fujii Y: Clinicopathological factors related to regrowth of vestibular schwannoma after incomplete resection. J Neurosurg 114:1224-1231, 2011

10. Gonzalez LF, Lekovic GP, Eschbacher J, Coons S, Spetzler RF: A true malignant schwannoma of the eighth cranial nerve: case report. Neurosurgery 61:E421-E422, 2007

11. Gruber B, Petchenik L, Williams M, Thomas C, Luken MG: Malignant vestibular schwannoma. Skull Base Surg 4:227231, 1994

12. Han DH, Kim DG, Chi JG, Park SH, Jung HW, Kim YG: Malignant triton tumor of the acoustic nerve. Case report. J Neurosurg 76:874-877, 1992

13. Hanabusa K, Morikawa A, Murata T, Taki W: Acoustic neuroma with malignant transformation. Case report. J Neurosurg 95:518-521, 2001

14. Harada K, Nishizaki T, Adachi N, Suzuki M, Ito H: Pediatric acoustic schwannoma showing rapid regrowth with high proliferative activity. Childs Nerv Syst 16:134-137, 2000

15. Hasegawa T, Kida Y, Kato T, Iizuka H, Kuramitsu S, Yamamoto T: Long-term safety and efficacy of stereotactic radiosurgery for vestibular schwannomas: evaluation of 440 patients more than 10 years after treatment with Gamma Knife surgery. J Neurosurg 118:557-565, 2013

16. Hernanz-Schulman M, Welch K, Strand R, Ordia JI: Acoustic neuromas in children. AJNR Am J Neuroradiol 7:519521,1986

17. Karami KJ, Kelkar PS, Verdon MP, Grills IS, Bojrab DI, Pieper DR: Malignant peripheral nerve sheath tumor of the vestibulocochlear nerve and brainstem: multimodality treatment with survival of 27 months. A case report and review of the literature. Neurosurgery 69:E1152-E1165, 2011

18. Kubo O, Chernov M, Izawa M, Hayashi M, Muragaki Y, Maruyama T, et al: Malignant progression of benign brain tumors after gamma knife radiosurgery: is it really caused by irradiation? Minim Invasive Neurosurg 48:334-339, 2005

19. Kudo M, Matsumoto M, Terao H: Malignant nerve sheath tumor of acoustic nerve. Arch Pathol Lab Med 107:293-297, 1983

20. Lunsford LD, Niranjan A, Flickinger JC, Maitz A, Kondziolka D: Radiosurgery of vestibular schwannomas: summary of experience in 829 cases. J Neurosurg 102 Suppl:195-199, 2005

21. Maeda M, Jozaki T, Baba S, Muro H, Shirasawa H, Ichihashi T: Malignant nerve sheath tumor with rhabdomyoblastic dif- 
ferentiation arising from the acoustic nerve. Acta Pathol Jpn 43:198-203, 1993

22. Markou K, Eimer S, Perret C, Huchet A, Goudakos J, Liguoro $\mathrm{D}$, et al: Unique case of malignant transformation of a vestibular schwannoma after fractionated radiotherapy. Am J Otolaryngol 33:168-173, 2012

23. Matsumoto M, Sakata Y, Sanpei K, Onagi A, Terao H, Kudo M: [Malignant schwannoma of acoustic nerve: a case report.] No Shinkei Geka 18:59-62, 1990 (Jpn)

24. McLean CA, Laidlaw JD, Brownbill DS, Gonzales MF: Recurrence of acoustic neurilemoma as a malignant spindle-cell neoplasm. Case report. J Neurosurg 73:946-950, 1990

25. Mrak RE, Flanigan S, Collins CL: Malignant acoustic schwannoma. Arch Pathol Lab Med 118:557-561, 1994

26. Patel TR, Chiang VLS: Secondary neoplasms after stereotactic radiosurgery. World Neurosurg 81:594-599, 2014

27. Saito T, Oki S, Mikami T, Kawamoto Y, Yamaguchi S, Kuwamoto K, et al: [Malignant peripheral nerve sheath tumor with divergent cartilage differentiation from the acoustic nerve: case report.] No To Shinkei 52:734-739, 2000 (Jpn)

28. Seferis C, Torrens M, Paraskevopoulou C, Psichidis G: Malignant transformation in vestibular schwannoma: report of a single case, literature search, and debate. J Neurosurg 121 Suppl:160-166, 2014

29. Scheithauer BW, Erdogan S, Rodriguez FJ, Burger PC, Woodruff JM, Kros JM, et al: Malignant peripheral nerve sheath tumors of cranial nerves and intracranial contents: a clinicopathologic study of 17 cases. Am J Surg Pathol 33:325-338, 2009

30. Schmitt WR, Carlson ML, Giannini C, Driscoll CL, Link MJ: Radiation-induced sarcoma in a large vestibular schwannoma following stereotactic radiosurgery: case report. Neurosurgery 68:E840-E846, 2011

31. Son EI, Kim IM, Kim SP: Vestibular schwannoma with malignant transformation: a case report. J Korean Med Sci 16:817-821, 2001

32. Tanbouzi Husseini S, Piccirillo E, Taibah A, Paties CT, Riz- zoli R, Sanna M: Malignancy in vestibular schwannoma after stereotactic radiotherapy: a case report and review of the literature. Laryngoscope 121:923-928, 2011

33. Wei C, Heman-Ackah SE, Newman K, Zagzag D, Golfinos JG, Roland JT Jr: Temporal bone histopathology case of the month: Malignant peripheral nerve sheath tumor arising within vestibular schwannoma. Otol Neurotol 33:e83-e84, 2012

34. Yanamadala V, Williamson RW, Fusco DJ, Eschbacher J, Weisskopf P, Porter RW: Malignant transformation of a vestibular schwannoma after gamma knife radiosurgery. World Neurosurg 79:593.e1-593.e8, 2013

35. Yokoyama M, Matsuda M, Nakasu S, Nakajima M, Handa J: Clinical significance of Ki-67 staining index in acoustic neurinoma. Neurol Med Chir (Tokyo) 36:698-703, 1996

\section{Disclosures}

The authors report no conflict of interest concerning the materials or methods used in this study or the findings specified in this paper.

\section{Author Contributions}

Conception and design: Fugleholm, Bashir, Poulsgaard. Acquisition of data: Bashir. Analysis and interpretation of data: Bashir, Broholm. Drafting the article: Bashir. Critically revising the article: all authors. Reviewed submitted version of manuscript: all authors. Approved the final version of the manuscript on behalf of all authors: Fugleholm.

\section{Correspondence}

Kåre Fugleholm, Department of Neurosurgery, Rigshospitalet, Faculty of Health and Medical Sciences, University of Copenhagen, Blegdamsvej 9, Copenhagen 2100, Denmark. email: kaare. fugleholm.buch@regionh.dk. 